\title{
Orthopaedics in day surgery
}

\author{
J.A.O. Mulimba, MBChB, MMed, FRCS, FCS (ECSA), L.N. Gakuu, MBChB, MMed, FCS (ECSA), Department of \\ Orthopaedics surgery, University of Nairobi, P.O. Box 52507-00200, Nairobi, Kenya and M.A. Odhiambo, KRN, \\ KRM, BSc N, Upper Hill Medical Centre, Nairobi, Kenya, Email: prof-jao@uhmc.co.ke
}

\begin{abstract}
Background: Day surgery is now well established worldwide, but is just being established in Africa. In this paper is examined the efficacy of day care surgery in Orthopaedics. Setting up of the units and types of units that are looked at.

Objective: To study the feasibility of day surgery in orthopaedics in an Urban African setting.

Setting: Two day surgical units, in Upper Hill Medical Centre and Menelik Medical Centre, Nairobi, Kenya.

Methods: Patients treated at two day surgical units study with the aid of careful record, as to the selection, treatment, complications and any other observations.
\end{abstract}

Results: Study period January 2003 to December 2008. Total operations were 6061 with 954 (16\%) being orthopaedics. There were 573 males and 381 females. Age range 2-75 years. All spectrum of orthopaedic operations done. Upper limb procedures were 527 and 330 lower limb. Twenty eight amputations were done of which four were major. Admissions were 13 and no infection or serious complications were reported.

Conclusion: Day care orthopaedics surgery in Africa is feasible and desirable with care preparations complications are few.

\section{INTRODUCTION}

Day or ambulatory surgery is the admission to hospital of selected, planned, non-emergency patients for a surgical procedure, returning home the same day (1). Ambulatory orthopaedics happens to have double meaning, so in this communication day surgery will be the preferred term. In Kenya the three models of day surgery units do exist. The commonest found in most of the public hospitals is where day surgery patients share wards and theatres with admitted patients. This renders day cases liable to missing theatre and is the most inefficient of the systems $(2,3)$. The second is that adopted in some of the private hospitals where there are separate wards and theatres for day cases. The processing of day cases is separate, more efficient and cases of cancellation are rare. The last system is that of a unit standing independent from an admitting hospital with theatres and wards committed to day surgery only. This is the most efficient of the three systems and probably costwise may be the better system. Its main limitation or requirement is that it must have a working arrangement with one or two hospitals in the vicinity to admit that odd case which gets complications or idiosyncrasy. The current situation in all the units in the country is that most units have leaned more towards minor surgery than undertaking complex surgeries. This state of affairs is changing with the increasing adoption of minimally invasive surgery in all surgical disciplines. Starting of a day surgery unit is an elaborate task requiring the collaborations of various health workers and administrators including financial controllers $(4,5)$. The authors have been involved in setting up of three day care units in Nairobi and these cover all the three systems already mentioned. Among the areas to be covered in planning are patient selection, review by anaesthetists, patient records, costing of procedures, drugs to be used and especially their side effects. Utilisation of theatre time, how long a case should take on average to avoid bringing to day case lengthy procedures likely to run into complications. Admission and discharge procedures different from inpatient ones. Extra care is taken to find out how patients come and leave hospital. This mentality of 'an operated African patient walking across the fields to get home' is archaic $(4,6,7)$. Various surgical specialists should list the kind of cases they think are safe to start with while evaluating the facilities. 
It is necessary to educate the patients on the advantages of day care surgery. All the eloquent arguments to health workers and health administrators don't necessarily attract patients. The single most persuasive argument, we found, is cost. If the patient is going to pay significantly less for the same procedure, then this will interest the patient. The next aspect of cost is to show insurances that it is to their advantage that the patients are treated on outpatient basis. Most insurances insist that they cover patients for inpatient treatment only.

The origins of day surgery go back to the days of Dr. Nicoll in Scotland in his treatment of children (8). In the United States of America (USA) Ambulatory Surgical Centres (ASC) were started in 1970 by two surgeons in Arizona (5). Since then the number of surgeries done on day care basis have risen to 22,000,000 a year. Each centre is by rule of the medicare and accreditation regulatory body required to have a back up plan for transfer of patients to a hospital in case need arises. There is audit of these day care centres every three years. The list of types of surgery in various specialties is endless, but in this article we look at the orthopaedic and orthopaedic trauma surgery in day surgery.

\section{MATERIALS AND METHODS}

Objective: The object of this study was to determine the practicality of day surgery in an urban African setting, the hurdles and outcomes of this surgery in orthopaedics and orthopaedic trauma.

Setting: Two day care hospitals in Nairobi. Upper Hill Medical Centre and MenelikHospital, one independently set and one as part of a hospital with an admitting wing.

Methods: Records of patients coming to either of these two centres for day surgery were carefully kept and all information recorded on a standard form. Patients were assessed in the clinics by a number of surgeons, after a decision was made that surgery was required, the patient was advised that he/she could be operated as in or outpatient. At the request of the patients the financial implications were explained. For minor cases, the patients were booked with the sister in theatre and patient given the date when to report. For major cases the following routine was followed. The patient was sent to the laboratory for blood investigations especially haemoglobin, urea and electrolytes. The patient was then sent for review by an anaesthetist and any other tests done as necessary. The type of anaesthesia was decided and the patient given time to arrive in the hospital on the operation date. Patients came starved whether going for general or regional anaesthesia. At discharge patients were given instructions to: Go to the nearest health institution or call the doctor in case of intractable pain, excessive swelling of the limb, loss of sensation in the limb or digits turning blue.

\section{RESULTS}

The study period was January 2003 to December 2008. Over the period a total of 6,061 operations were done in the two clinics. Of these 954(16\%) were orthopaedics. There were 573 males to 381 females a ratio of male to female of $3: 2$. The age range was $2-75$ years.

Table 1

Regional distribution of procedures

\begin{tabular}{lc}
\hline Procedures & No. of patients \\
\hline Upper Limb & 527 \\
Lower Limbs & 330 \\
Others & 97 \\
\hline Total & 954 \\
\hline
\end{tabular}

The procedures carried out included open reduction and fixation of fractures, removal of metals, amputations, sequestrectomies, removal of lumps and cysts, manipulations under anaesthesia, arthroscopies of the knee, tendon and nerve repairs and other minor and not so minor procedures.

Table 2

Some major operations done

\begin{tabular}{lccc}
\hline & $\begin{array}{c}\text { Upper } \\
\text { limb }\end{array}$ & $\begin{array}{c}\text { Lower } \\
\text { limb }\end{array}$ & Total \\
\hline ORIF & 125 & 85 & 210 \\
Sequestrectomies & 7 & 27 & 34 \\
Removal of metals & 35 & 58 & 93 \\
*Amputations & 8 & 20 & 28 \\
Others & 352 & 140 & 492 \\
\hline Total & 527 & 330 & 857 \\
\hline
\end{tabular}

Key: ORIF - Open reduction and internal fixation.

* Amputation including fingers and toes. 
Table 3

Amputations

\begin{tabular}{lc}
\hline Amputations & No. of patients \\
\hline Above knee & 1 \\
Below knee & 2 \\
Above elbow & 1 \\
Toes and fingers & 24 \\
\hline Total & 28
\end{tabular}

There were thirteen patients admitted after surgery.

Table 4

Patients admitted after surgery

\begin{tabular}{lc}
\hline Type of surgery & No. of patients \\
\hline Plating humerus & 5 \\
Plating femur & 2 \\
Plate removal femur & 1 \\
Sequestrectomy femur & 4 \\
Sequestrectomy tibia & 1 \\
\hline Total & 13 \\
\hline
\end{tabular}

Table 5

Reasons for admissions

\begin{tabular}{lc}
\hline Reason & No. of patients \\
\hline Late recovery & 4 \\
Pain & 7 \\
Bleeding & 2 \\
\hline
\end{tabular}

\section{DISCUSSION}

There were 6016 cases operated in the two day care units over the period of study, five years. The same period the next five years will show much larger figures as the figures have been improving with each passing year. The reasons for initial small numbers were being a little over cautious, reluctance on the patients' part and the resistance of insurances to use day surgery. Other reasons included few orthopaedic surgeons, lack of knowledge, pecuniary interests as admissions pay better and lack of specialized equipment in the day care units. However, with time things are changing and insurances becoming more receptive to day surgery. The fact that out of the total figure of 6,016 operations, only 954 were orthopaedics shows how slow orthopaedics has been in catching up with the trend with reasons already given above. Trauma, especially road traffic accidents is one of the commonest causes of disease in this country (9).

The preponderance of males over females 3:2 ratio is a reflection of the increased number of males over females in tauma (9). Orthopaedics deals mostly with locomotion, this utilises the lower limbs more, so it is little wonder that upper limb surgery accounted for more cases than the lower limb at 527:330 giving a ratio of about 3:2.

It is evident from the results that the entire scope of orthopaedics was covered in the realm of orthopaedics and trauma, 210 cases were done open reduction and internal fixation. It is notable that no major infection is reported in the series. It may just be that the numbers are small or that some of the minor infections that occurred were not reported. It also goes to show that cross patient infection is minimized when patients are treated outside the hospital wards (10). However, without exception, all cases of open reduction were discharged on antibiotics (11). This aspect will need to be studied further by determining the microbiological population of patients operated and sensitivity patterns. The risk of development of antibiotic resistance cannot be underestimated, but then the legal implications are also a problem.

There were more metals removed from the lower limbs than the upper limbs. There are two possible explanations $(12,13)$. Most upper limb fixations especially in the fingers were done with Kirschner wires and are usually pulled out in the clinic. The lower limb fixations are mostly done as major undertakings and metals cannot be removed in the clinic. Secondly major fixations affect the lower limb more than the upper limb. Another area where major lower limb surgery is done as outpatient procedure is arthroscopy. In our set up the majority of these are still done as inpatient.

Although there were 28 amputations in this series, only four were major. Amputation is a very traumatic event both physically and psychologically so it was mostly considered prudent to do these as inpatients to give patients time to adjust to the changed circumstances in hospital.

There were 13 patients admitted after surgery originally intended to be day surgery. This can be looked at as a failure in selection of cases. This may be not entirely correct as the majority were major cases and were admitted because of pain. It is also a call to review post operative analgesia so that a safe and effective home administered analgesia is found. Currently most 
of the patients are controlled with injections of opiates. Some patients were admitted because of late recovery signifying that the operations were done late in the day or the patient reacted unexpectedly to the anaesthesia. The anaesthetic used was both general and regional, but further analysis of this will be published later, however suffice to point out that anaesthetists are still reluctant to use spinal anaesthesia in day surgery. Bleeding was a reason for admission in two patients only. Adequate discharge instructions eliminated tragedies that would have otherwise befallen some of our patients.

\section{CONCLUSIONS}

Day surgery is feasible and desirable in urban centres in Africa and should be exploited further to help ease congestion in our hospitals. This study shows that with adequate preparations much orthopaedic surgery can be done in day care setup and is safe. The role of education to medical services providers and funders is incalculable. Careful instructions to the patients or relatives at discharge does a lot to minimize mishaps.

\section{RECOMMENDATIONS}

It is recommended that day care surgery be encouraged in orthopaedics to ease congestions in orthopaedic wards. Further studies be done to determine which of the three types of day care surgery systems would be most practical and cost effective. The type of anaesthesia and post operative analgesia will need further studies to determine efficacy and safety.

\section{REFERENCES}

1. Castoro C. Ambulatory surgery: Current status and future trends. East and Cent. Afr. J. Surg. 2006; 11: 67-68.

2. Dacum N.K., Ramyil V.M., Misano M.A., et al. Reasons of cancellations of urologic day care surgery. Nigerian J. Surg. Res. 2006; 8: 30-33.
3. Fadiora S.O., Kalawole I.K.,Alatoke S.A., et al. Day case surgery: Experience in a tertiary health institution in Nigerian. West Afr. J. Med. 2007; 26: 24-27.

4. Castoro C., Rampados, Nassali G, Kakande I, et al. Development of a day surgery programme in an urban Hospita in Africa. A model for developing countries. East \& Central Afr. J. Surg. 2006; 11: 69-70.

5. Small N.C. and Bert J.M. Perspectives in mordern orthopaedics - office ambulatory surgery centres: Creation and management. J. Amer. Aca. Ortho. Surg. 2003; 11: 157-162.

6. Kakande I., Obote W.W. and Sebbale K. Surgical camps: The Uganda experience. East \& Cent. Afr. J. Surg. 2001; 6: 41-44.

7. Kakande I., Nassali G. and Kituuka O. Day care surgery: The norm for elective surgery. East \& Cent. Afr. J. Surg. 2005; 10: 1-4.

8. Nicoll J.H. The surgery of infancy; Brit. Med. J. 1909; 18: 753-755

9. Muyembe V.M. and Mulimba J.A.O. A study of road traffic accidents as seen at Kenyatta National Hospital. Medicom. 2000; 15: 93-101.

10. Gakuu L.N. Surgical wound infections, their causes and management. East. Afr. Med. J. 2005; 7: 329-330.

11. Usang U.E., Sowande O.A., Adejuyigba O., et al. The role of pre-operative antibiotics in the prevention of wound infection after day case surgery for inguinal hernia in children in Ile Ife Nigeria: Paediat. Surg. Int. 2008; 24: 1181-1186.

12. Karol L.A. Perspectives on modern orthopaedics surgical management of the lower extremity in ambulatory children with cerebral palsy.J. Amer. Aca. Ortho. Surg. 2004; 12: 196-2003.

13. Depreitere B. Lumbar microdiscetomy in a day surgery setting. Surg. Neur. 2009; 71: 140. 